\title{
Identification of potential biomarkers related to glioma survival by gene expression profile analysis
}

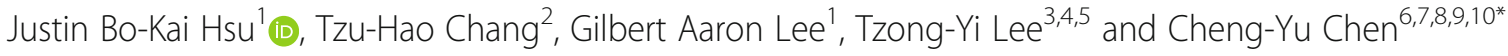

From 17th International Conference on Bioinformatics (InCoB 2018)

New Delhi, India. 26-28 September, 2018

\begin{abstract}
Background: Recent studies have proposed several gene signatures as biomarkers for different grades of gliomas from various perspectives. However, most of these genes can only be used appropriately for patients with specific grades of gliomas.

Methods: In this study, we aimed to identify survival-relevant genes shared between glioblastoma multiforme (GBM) and lower-grade glioma (LGG), which could be used as potential biomarkers to classify patients into different risk groups. Cox proportional hazard regression model (Cox model) was used to extract relative genes, and effectiveness of genes was estimated against random forest regression. Finally, risk models were constructed with logistic regression.

Results: We identified 104 key genes that were shared between GBM and LGG, which could be significantly correlated with patients' survival based on next-generation sequencing data obtained from The Cancer Genome Atlas for gene expression analysis. The effectiveness of these genes in the survival prediction of GBM and LGG was evaluated, and the average receiver operating characteristic curve (ROC) area under the curve values ranged from 0.7 to 0.8 . Gene set enrichment analysis revealed that these genes were involved in eight significant pathways and 23 molecular functions. Moreover, the expressions of ten (CTSZ, EFEMP2, ITGA5, KDELR2, MDK, MICALL2, MAP 2 K3, PLAUR, SERPINE1, and SOCS3) of these genes were significantly higher in GBM than in $L G G$, and comparing their expression levels to those of the proposed control genes (TBP, IPO8, and SDHA) could have the potential capability to classify patients into high- and low- risk groups, which differ significantly in the overall survival. Signatures of candidate genes were validated, by multiple microarray datasets from Gene Expression Omnibus, to increase the robustness of using these potential prognostic factors. In both the GBM and LGG cohort study, most of the patients in the high-risk group had the IDH1 wild-type gene, and those in the low-risk group had IDH1 mutations. Moreover, most of the high-risk patients with LGG possessed a 1p/19q-noncodeletion.

Conclusion: In this study, we identified survival relevant genes which were shared between GBM and LGG, and those enabled to classify patients into high- and low-risk groups based on expression level analysis. Both the risk groups could be correlated with the well-known genetic variants, thus suggesting their potential prognostic value in clinical application.
\end{abstract}

Keywords: Low-grade glioma (LGG), High-grade glioma, Gene signature, Biomarkers, Prognosis

\footnotetext{
* Correspondence: sandy0932@gmail.com

${ }^{6}$ Research Center of Translational Imaging, College of Medicine, Taipei

Medical University, Taipei 110, Taiwan

${ }^{7}$ Department of Radiology, School of Medicine, College of Medicine, Taipei

Medical University, Taipei 110, Taiwan

Full list of author information is available at the end of the article
}

(C) The Author(s). 2019 Open Access This article is distributed under the terms of the Creative Commons Attribution 4.0 International License (http://creativecommons.org/licenses/by/4.0/), which permits unrestricted use, distribution, and reproduction in any medium, provided you give appropriate credit to the original author(s) and the source, provide a link to the Creative Commons license, and indicate if changes were made. The Creative Commons Public Domain Dedication waiver (http://creativecommons.org/publicdomain/zero/1.0/) applies to the data made available in this article, unless otherwise stated. 


\section{Background}

Glioma is a common type of primary central nervous system (CNS) tumor which arises from glial cells [1]. Following the World Health Organization (WHO) classification in 2007, gliomas can be subdivided into grade II, grade III, and grade IV (glioblastoma multiforme, GBM), depending on the degree of aggressiveness [2, 3]. In "The Cancer Genome Atlas" (TCGA) database, grade II and III are classified as lower-grade glioma (LGG), and grade IV as GBM. Despite developments in therapies that include surgical resection, chemotherapy, and radiotherapy, the median survival and prognosis remain poor, particularly for glioblastoma patients $[4,5]$. The median overall survival time (mOS) of GBM is approximately 1.25 years $[5,6]$, and that of LGG is $6.5-8$ years $[7,8]$. Thus, it is important to elucidate the survival events of glioma, which could potentially aid in the diagnosis and prognosis of glioma patients.

Patient survival time with regards to tumor progression is associated with various subtypes and grades of the tumor [2]. The histological classification of tumor subtypes is important to guide treatment decisions, which are often combined with several clinical prognostic features. In neuro-oncological practice, however, no clear national consensus for adult glioma diagnosis has been reached and the diagnosis is subject to interobserver variation $[9,10]$; only utilizing histological information in studying various types of gliomas is restricted. On the other hand, previous studies have shown that gene expression profiling provides an objective method to classify tumors [11, 12]; it is better to correlate gene expression profiling, rather than tumor histology, with prognosis [13]. Moreover, it may even be utilized to predict patients' prognosis from various points of view [14-29]. Comparing these gene lists published from 2004 to 2016, it is observed that the genes identified from various research groups are quite different. This observation indicates that glioma patients' overall survival (OS) is correlated with many kinds of events caused by various expression profiles of multiple genes. Therefore, extraction of comprehensive survival-related genes associated with gliomas is required, and it is possible for researchers to carry out further relevant studies. In addition, most previous studies [14, 18-23, 25-27, 29] have only utilized microarray datasets, rather than different kinds of datasets such as next-generation sequencing (NGS) data, to screen expression profiles of genes might have unexpected data bias; generally, utilizing NGS to detect gene signatures might be more precise than array data.

In this study, we aimed to identify common genes correlated with the overall survival of gliomas following the association of their expression profiles and patients' survival time. Candidate genes were extracted from GBM and LGG study cohorts after analysis of NGS datasets from TCGA and validation by microarray datasets from Gene Expression Omnibus (GEO). Of these survival-related genes, the critical ones, which were potential biomarkers, were further analyzed and filtered, and then used to construct the survival-relevant risk models for clinical application against gliomas.

\section{Methods}

Patients and gene expression datasets

Publicly available gene expression datasets of patients with glioma were obtained from TCGA (https://cancer genome.nih.gov/) and the GEO (https://www.ncbi.nlm. nih.gov/geo/). From TCGA projects (TCGA-LGG and TCGA-GBM), level 3 RNA-Seq datasets and their clinical information were used to investigate the relationship between gene expression and patient survival. The microarray datasets (GSE16011, GSE4412, and GSE4271) from the GEO were utilized to confirm and validate the results obtained based on the TCGA datasets. Notably, grades II and III of gliomas were included in the TCGA-LGG project, whereas grade IV was studied in a separate project, namely TCGA-GBM. Following the project definition, patients from GEO datasets could be divided into LGG and GBM categories. The sample sizes of various datasets are summarized in Table 1, and the detailed clinical and histological characteristics of patients are listed in Table 2.

In this study, NGS datasets were used for the main analysis because of their advantages of low data bias and large sample size. The median OS of patients with gliomas based on their various histological subtypes was estimated using the Kaplan-Meier curve (Fig. 1). The median OS of patients with LGG and those with GBM were determined as approximately 2700 and 450 days, respectively.

The level-3 data (RNA-Seq) obtained from TCGA utilized the fragments per kilobase of transcript per million

Table 1 Statistics of datasets from TCGA and GEO databases

\begin{tabular}{|c|c|c|c|c|}
\hline & TCGA (RNA-Seq) & GEO GSE16011) & GEO (GSE4412) & GEO (GSE4271) \\
\hline GBM & 154 & 159 & 59 & 76 \\
\hline LGG & 516 & 109 & 26 & 24 \\
\hline GBM with surv. Info. & 152 & 155 & 59 & 56 \\
\hline LGG with surv. Info. & 511 & 109 & 26 & 21 \\
\hline
\end{tabular}

When the analysis of gene expression must be correlated to survival information, the sample size of datasets would be possible to become smaller 
Table 2 Clinical and histological characteristics of patients with glioma

\begin{tabular}{|c|c|c|c|c|c|c|c|c|}
\hline & TCGA (RNA-S & & GSE16011 & & GSE4412 & & GSE4271 & \\
\hline & LGG & GBM & LGG & GBM & LGG & GBM & LGG & GBM \\
\hline & 516 & 154 & 109 & 159 & 26 & 59 & 24 & 76 \\
\hline Sex & & & & & & & & \\
\hline Male & 285 & 99 & 72 & 108 & 6 & 26 & 16 & 52 \\
\hline Female & 230 & 54 & 37 & 51 & 20 & 33 & 8 & 24 \\
\hline Unknown & 1 & 1 & & & & & & \\
\hline Age & & & & & & & & \\
\hline Median (LQ-UQ) & $41(32-53)$ & $60(52-70)$ & $44(37-55)$ & $55(46-64)$ & $34(31-41)$ & 47 (39-61) & $35(32-43)$ & $49(40-55)$ \\
\hline Histology & & & & & & & & \\
\hline Astro. & $194(37.6 \%)$ & & 29 (24.8\%) & & $8(30.8 \%)$ & & & \\
\hline GBM & & $154(100 \%)$ & & 159 (100\%) & & 59 (100\%) & & \\
\hline Oligoastro. & $130(25.2 \%)$ & & $28(23.9 \%)$ & & 7 (26.9\%) & & & \\
\hline Oligodendro. & 191 (37.0\%) & & $52(44.4 \%)$ & & $11(42.3 \%)$ & & & \\
\hline Pilocytic Astro. & & & & & & & & \\
\hline Unknown & $1(0.2 \%)$ & & & & & & & \\
\hline Tumor grade & & & & & & & & \\
\hline G1 & & & & & & & & \\
\hline G2 & $249(48.3 \%)$ & & $24(20.5 \%)$ & & & & & \\
\hline G3 & $266(51.6 \%)$ & & 85 (73.7\%) & & $26(100 \%)$ & & 24 (100\%) & \\
\hline G4 & & $153(99.4 \%)$ & & 159 (100\%) & & 59 (100\%) & & 76 (100\%) \\
\hline Unknown & $1(0.1 \%)$ & $1(0.6 \%)$ & & & & & & \\
\hline
\end{tabular}

mapped reads (FPKM) [30] to determine the expression level of genes. The formula for FPKM is as follows:

$$
\mathrm{FPKM}=\frac{\text { total fragments }}{\text { mapped reads }(\text { millions }) * \text { exon length }(\text { kilobase pair })}
$$

After exclusion of genes that were not expressed in all patients, 19,924 genes were eligible for further analysis of the LGG and GBM cohorts from TCGA projects. Gene expression analysis of microarrays belonging to the GBM and LGG populations from the GEO database were first normalized using the $\mathrm{R}$ function normalize.quantiles [31].

\section{Analysis workflow of this study}

This study was divided into two major parts. In the first part, survival-related genes were identified and their effectiveness in relation to the survival of patients with GBM and LGG was evaluated. In the second part, a representative subset of these genes that could help in differentiating between high- and low-risk patients was identified (Fig. 2). The first part focused on profiling gene signatures that corresponded with the patients' OS; these genes were termed survival-related genes. The performance evaluation of survival predictors for GBM and LGG indicated that these genes were closely correlated with patient outcomes (survival time). Subsequently, gene set enrichment analysis using various tools was performed on these genes (not shown in the Fig. 2). In the second part, we used additional microarray datasets to further filter genes whose expression trends between the LGG and GBM groups were consistent with the results of the analysis of the NGS datasets and may have been applicable for classification of patients into risk groups (high-risk patients have shorter OS; low-risk patients have longer OS). The size of the gene set was gradually scaled down and is annotated in Fig. 2 after several filtering steps using various criteria.

\section{Identification of significant survival-related genes}

The Cox proportional hazards regression model ("Cox model" hereafter; survival analysis) was used to identify possible factors that might be associated with patients' OS duration. In this study, univariate Cox regression analysis [32] was performed to assess the expression profiles of genes that might be significantly correlated with the survival time of patients with GBM or LGG. Subsequently, these putative survival-related genes were ranked and filtered by applying stringent criteria (hazard ratio $[\mathrm{HR}]>1$; Wald test, $p<0.01$ ). Each extracted gene was consequently analyzed to evaluate the correlation of its expression level with various survival durations in patients. Here, the median OS (in days) of 


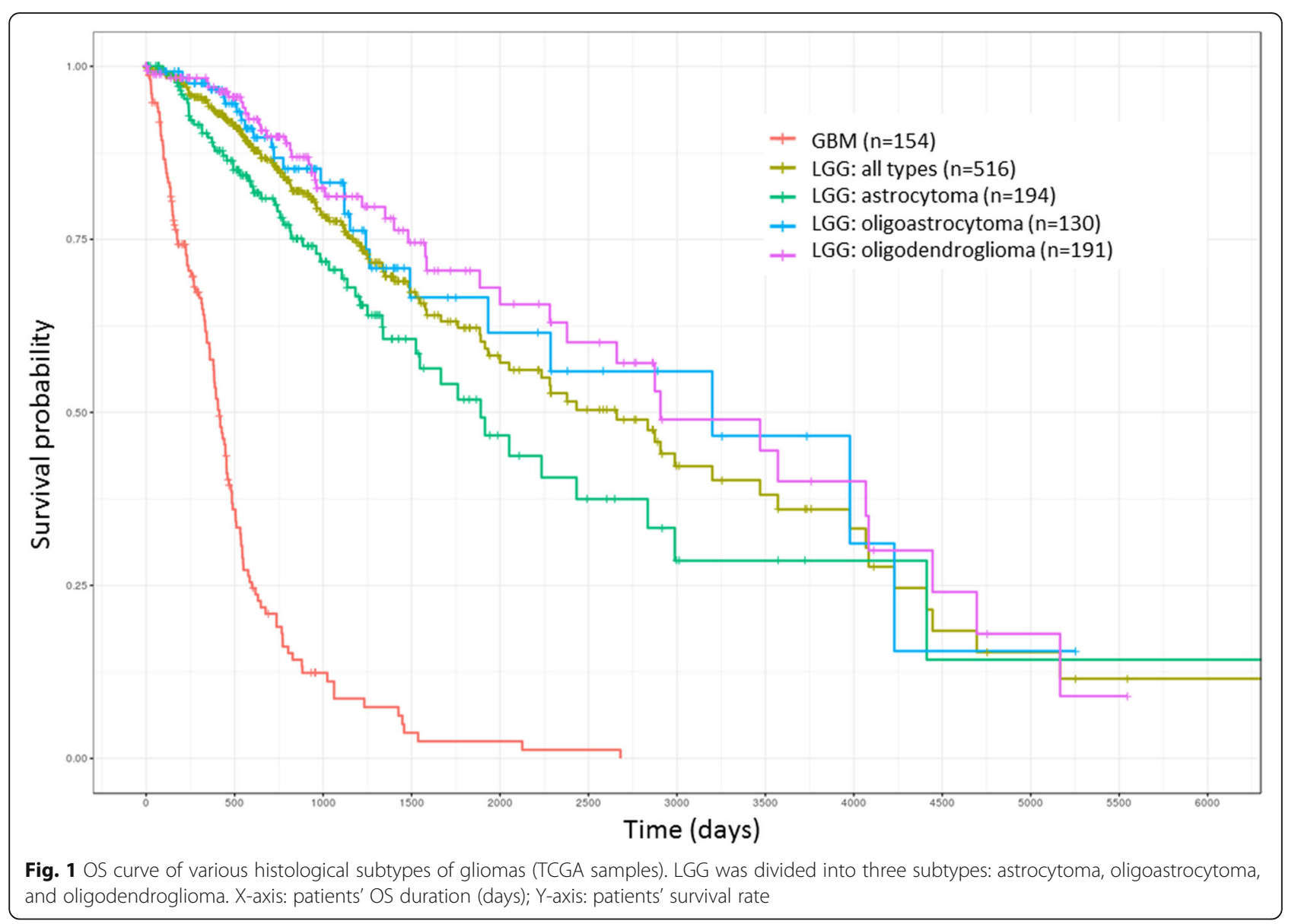

GBM and LGG groups would be set as an important time point for both groups, respectively, to separate patients into shorter or longer survival durations, to recognize that the expression levels of genes differed significantly between the survival durations (number of days to death less or more than the median OS). The Student's $t$-test $(p<0.05)$ was conducted to select statistically significant candidate genes.

\section{Building survival predictive models for patients with GBM and LGG}

The predictive model for survival analysis in this study was built using randomForestSRC [33-35], a nonparametric machine learning method. Moreover, because it can combine the results of many survival trees, this model is arguably more objective than other methods. Accordingly, the expression profiles of candidate genes related to survival durations were used to construct survival predictors for GBM and LGG. To assess the performance of the predictors, 1000 repetitions of five-fold cross-validation were performed, $80 \%$ of the samples were employed as the training dataset to train the model, and the remaining $20 \%$ served as the validation dataset. Receiver operating characteristic curves (ROC) obtained from the 1000 iterations were evaluated using a boxplot with their area under curve (AUC) values. The performance could be used to realize the importance of these candidate genes to GBM and LGG.

\section{Gene set enrichment analysis}

Ingenuity pathway analysis (IPA) software (Qiagen), GeneAnalytics [36], and DAVID [37, 38] were used to analyze the biological roles and molecular functions of candidate genes identified from patients with glioma. Survival-related genes common to both LGG and GBM could be useful in realizing shared functions; the pathways in both study cohorts were related to patient survival.

In this study, multiple gene set enrichment analysis tools were applied to increase the consistency and accuracy of the results. The functions and pathways that the gene set was involved were identified using at least two kinds of tools.

Gene expression level analysis between GBM and LGG The survival-related genes with varying expression levels in case of relative high-risk (GBM) and relative low-risk (LGG) of gliomas would be further analyzed and could be used as putative biomarkers. A previous study 


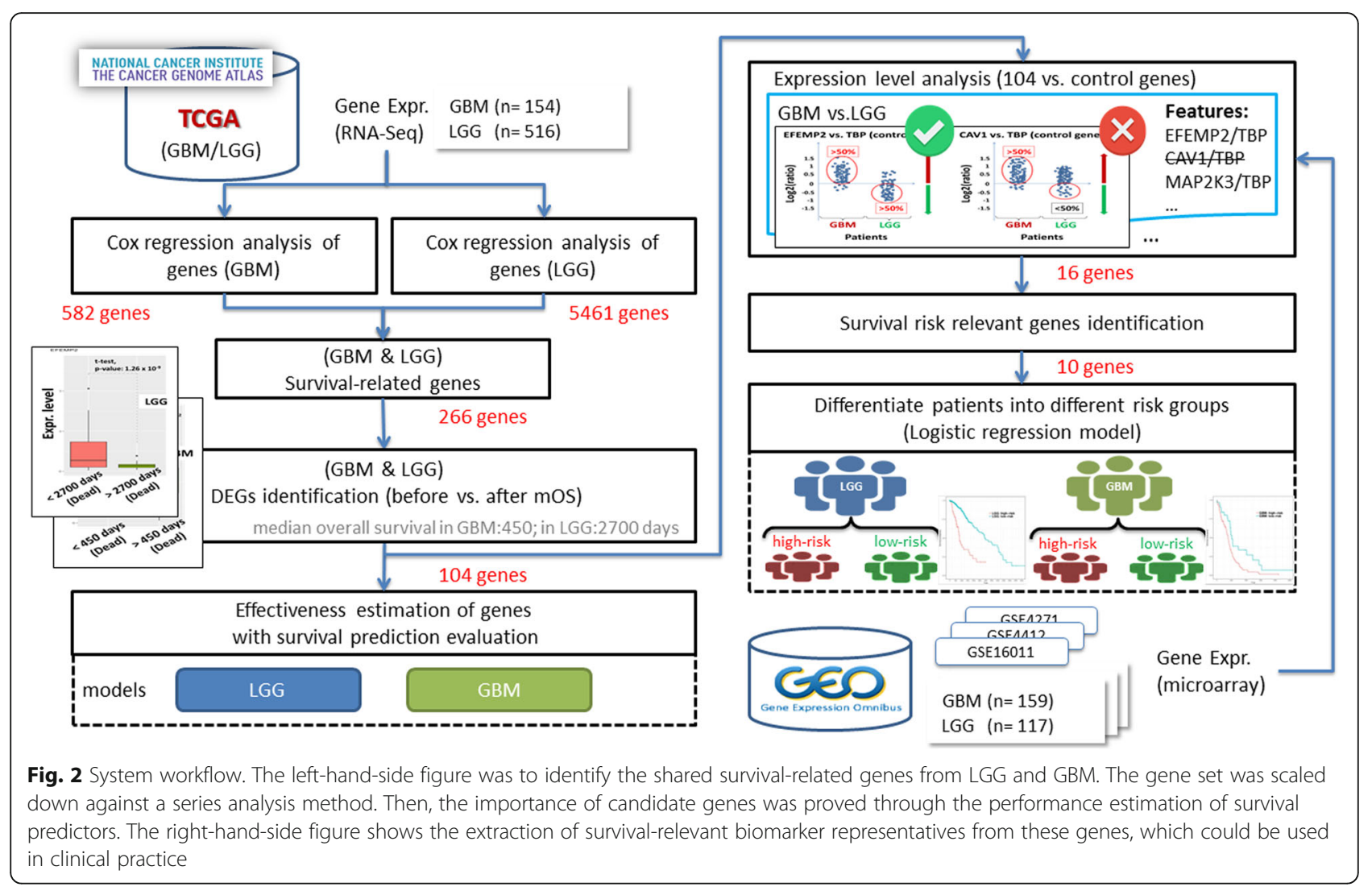

demonstrated that the following five endogenous control genes were not differentially expressed between the glioma and normal brain: TBP, IPO8, GAPDH, RPL13A, and SDHA [39]. Therefore, the $\log 2$-fold changes in the expression of these survival-related genes relative to those of the control genes were calculated; there were $p \times$ $q$ unique features (the signatures of genes were higher or lower than those of the control genes) for each patient, when $p$ survival-related genes and $q$ control genes were present. For each feature, the percentages of patients with high and low expression were calculated and screened. If a gene expression was both high (or low) in over $50 \%$ of patients with GBM and low (or high) in over $50 \%$ of those with LGG, compared with the expression of the control genes, the log2-fold change value was used as a feature in this study. Subsequently, features with different expression levels between GBM and LGG were retained as the candidates of risk descriptors. For instance, the survival-related gene TIMP1- which had high expression in $98 \%$ of patients with GBM but low expression in $60 \%$ of patients with LGG compared with the reference gene TBP - was retained. In addition to RNA-Seq datasets (TCGA), three distinct microarray datasets (GEO) were utilized to validate the consistency of various gene signatures in both classes of patients, in order to increase the data strength.

\section{Survival risk relevant genes identification}

The median OS days of GBM and LGG were notably different, implying that patients with GBM have a shorter survival time (relative to high-risk) and those with LGG have longer survival time (relative to low-risk). Under this assumption, survival-related genes were first filtered (using the method mentioned in the previous section) as possible descriptors to classify patients into risk groups. However, the effectiveness of these genes needed to be determined for further analysis using a statistical model. A logistic regression model $\left(Y=X_{1} \times \beta_{1}+X_{2} \times \beta_{2}+\ldots+X_{n} \times \beta_{n}+k\right)$ was applied to evaluate the importance of these features, namely the survival-related genes versus the control genes. Here, $Y$ is the estimated value of glioma prognosis risk (GBM defined as 1 , LGG defined as 0 ), $X$ represents the value of the $\log 2$-fold change of each feature, $\beta$ is the unknown coefficient, and $k$ is the unknown constant. The Akaike information criterion (AIC) was utilized to evaluate the relative quality of all models, which were constructed with various combinations of features. While repeating the process (backward elimination) to construct the logistic regression model, features with low predictive value for glioma prognosis were excluded each time until the number of features that provided the smallest AIC values was reached. Consequently, these features 


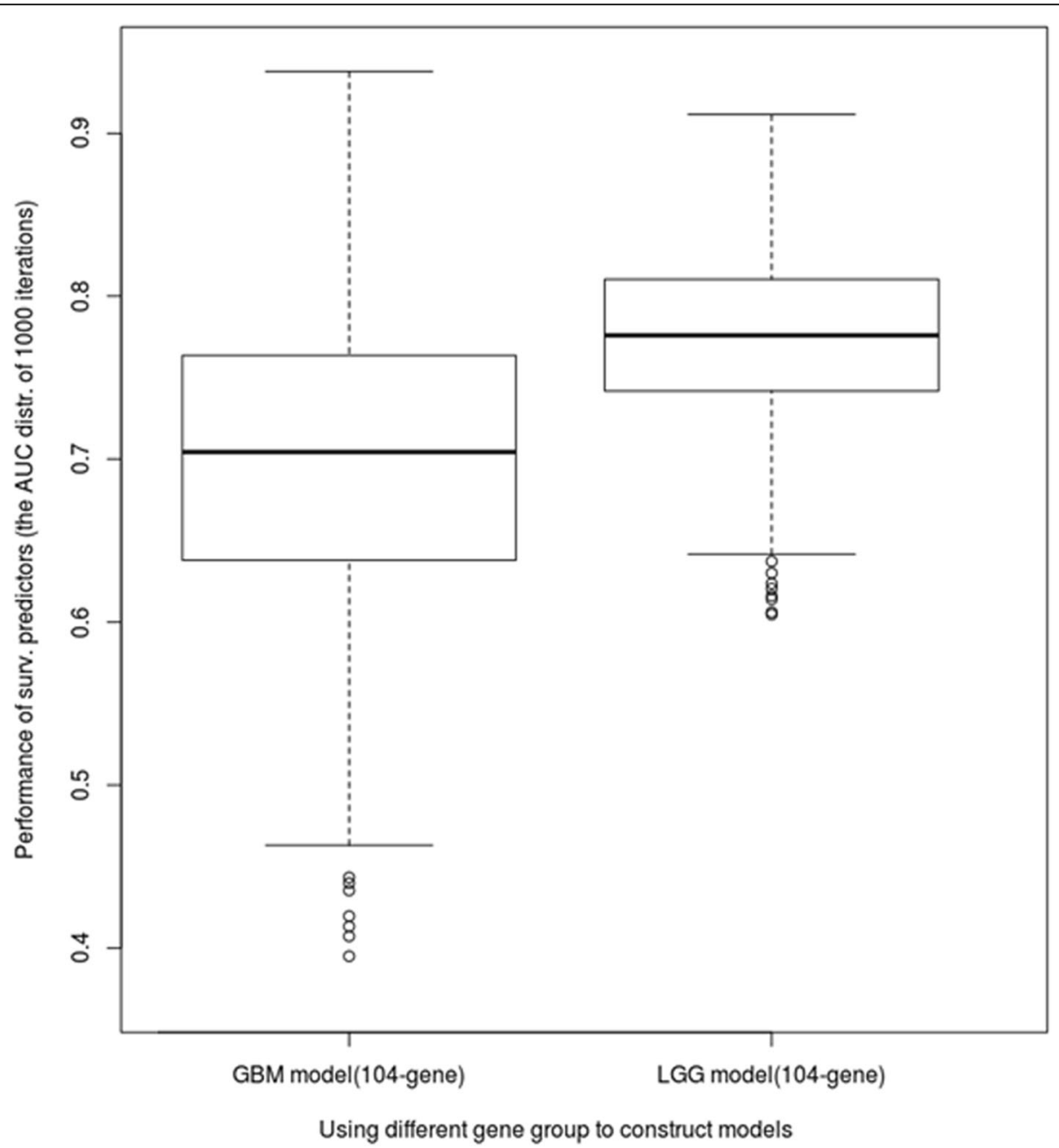

Fig. 3 Performance estimation of survival prediction models using the 104-gene group (TCGA samples). The X-axis represents two survival prediction models that were constructed with the 104 survival-related genes; one model was constructed for GBM and the other, for LGG. The Yaxis represents the distribution of AUC values after 1000 repetitions of 5-fold cross-validation

would be capable of recognizing the survival risk of patients with GBM or LGG; thus, the expression level of those genes relative to that of the control genes could be correlated to patients' survival.

\section{Differentiation of patients into different risk groups}

After the candidate features (from previous section: Survival risk relevant genes identification) had been identified, they could be used directly to create risk models for

Table 3 Capability estimation of 104 key genes for GBM and LGG survival prediction

\begin{tabular}{lll}
\hline Type & GBM & LGG \\
\hline Minimum & 0.40 & 0.60 \\
Maximum & 0.94 & 0.91 \\
Mean & 0.70 & 0.77 \\
Standard deviation & 0.09 & 0.05 \\
\hline
\end{tabular}

Table 4 Pathways summarized from the enrichment analysis of the 104 survival-related genes

\begin{tabular}{llll}
\hline Pathway & GeneAnalytics & IPA & DAVID \\
\hline ERK signaling & $\checkmark$ & $\checkmark$ & \\
Integrin pathway & $\checkmark$ & $\checkmark$ & \\
Akt signaling & $\checkmark$ & $\checkmark$ & \\
Phospholipase-C pathway & $\checkmark$ & $\checkmark$ & \\
Inhibition of matrix metalloproteases & & $\checkmark$ & $\checkmark$ \\
TNF signaling pathway & $\checkmark$ & & $\checkmark$ \\
Hematopoietic cell lineage & $\checkmark$ & & $\checkmark$ \\
Jak-STAT signaling pathway & & $\checkmark$ & $\checkmark$ \\
\hline
\end{tabular}


GBM and LGG. Logistic regression was applied to construct both risk models. Here, the outcome variable $Y$ was the estimated GBM or LGG prognosis risk (patients can't live over mOS are relative high risk and can live longer than mOS are low risk); for the GBM risk model, survival durations shorter than 450 days were defined as 1 and those longer than 450 days are defined as 0 . Similarly, for the LGG risk model, survival durations shorter than 2700 days were defined as 1 and those longer than survival durations longer than 2700 days were defined as 0 . The variable $X$ would be substituted into the $\log 2$-fold change value of the candidate features. The other variables, such as $\beta$ and $k$ were then estimated with the $\mathrm{R}$ package generalized linear models (glm) function for GBM and LGG risk model, respectively. In addition, 1000 repetitions of the five-fold cross-validation were run to evaluate the GBM and LGG models, which were used to classify patients into different risk groups.

\section{Results}

\section{GBM and LGG shared key survival-related genes}

In this study, using gene expression profiling, we identified 104 genes that were significantly correlated with OS in patients with GBM and those with LGG. After application of the stringent criteria to filter the putative survival-related genes using the Cox model, the expression signatures of 582 and 5461 genes were identified and correlated to OS in case of GBM $(n=152)$ and LGG $(n=511)$, respectively. Subsequently, 266 genes were obtained through the gene lists from both study cohorts. However, only 104 of these genes were also significantly differentially expressed (t-test, $p<0.05$ ) before and after the median OS time in the GBM and LGG study cohorts; these 104 survival-relevant genes are listed in Additional file 1: Table S1.

\section{Effectiveness estimation of 104 genes for GBM and LGG survival}

In order to estimate the effectiveness of the 104 shared survival-related genes, two survival prediction models were constructed with 1000 iterations of five-fold cross-validation for the GBM and LGG cohorts. The area under the curve (AUC) value distribution under the 1000-time simulation was illustrated using the boxplot and summarized (Fig. 3; Table 3). The mean AUC values of the GBM and LGG models were estimated

Table 5 Molecular and cellular functions summarized from the enrichment analysis of the 104 survival-related genes

\begin{tabular}{|c|c|c|c|}
\hline Molecular and cellular function & GeneAnalytics & IPA & DAVID \\
\hline Endodermal cell differentiation & $\checkmark$ & & $\checkmark$ \\
\hline Chemotaxis & $\checkmark$ & & $\checkmark$ \\
\hline T-cell activation & $\checkmark$ & & $\checkmark$ \\
\hline Extracellular matrix organization & $\checkmark$ & & $\checkmark$ \\
\hline Decidualization & $\checkmark$ & & $\checkmark$ \\
\hline Cytokine-mediated signaling pathway & $\checkmark$ & $\checkmark$ & $\checkmark$ \\
\hline Heterotypic cell-cell adhesion & $\checkmark$ & & $\checkmark$ \\
\hline Angiogenesis & $\checkmark$ & & $\checkmark$ \\
\hline Adaptive immune response & $\checkmark$ & & $\checkmark$ \\
\hline Integrin-mediated signaling pathway & $\checkmark$ & $\checkmark$ & $\checkmark$ \\
\hline Positive regulation of cell-substrate adhesion & $\checkmark$ & & $\checkmark$ \\
\hline Substrate-adhesion-dependent cell spreading & $\checkmark$ & & $\checkmark$ \\
\hline Positive regulation of tyrosine phosphorylation of Stat3 protein & $\checkmark$ & & $\checkmark$ \\
\hline Collagen fibril organization & $\checkmark$ & & $\checkmark$ \\
\hline Negative regulation of JAK-STAT cascade & $\checkmark$ & & $\checkmark$ \\
\hline Spongiotrophoblast differentiation & $\checkmark$ & & $\checkmark$ \\
\hline Leukocyte migration & $\checkmark$ & & $\checkmark$ \\
\hline Skeletal system development & $\checkmark$ & $\checkmark$ & $\checkmark$ \\
\hline T-cell migration & $\checkmark$ & & $\checkmark$ \\
\hline Positive regulation of $\mathrm{T}$ cell proliferation & $\checkmark$ & $\checkmark$ & $\checkmark$ \\
\hline Regulation of vesicle-mediated transport & $\checkmark$ & & $\checkmark$ \\
\hline positive regulation of $\mathrm{T}$ cell chemotaxis & $\checkmark$ & & $\checkmark$ \\
\hline Movement of cell or subcellular component & & $\checkmark$ & $\checkmark$ \\
\hline
\end{tabular}


approximately from 0.7 to 0.8 and the standard deviations were from 0.05 to 0.09 . Therefore, it was seen that the 104 genes affected the survival durations of patients with GBM and LGG to a certain extent.

\section{Pathway involvement and function category of survival- related genes}

The 104 genes identified were common regulators related to the survival of GBM and LGG and were further analyzed for their involvement in pathways and possible biological roles. The results overlapped in at least two of the three tools; eight pathways were identified as core pathways (Table 4). Half of these pathways were signal transduction pathways correlated with cell survival, death, and growth. The molecular and cellular functions of the 104-gene group could be characterized using 23 biological functions (Table 5). In addition, IPA analysis revealed that these genes were able to be correlated to several mechanism disorders such as those related to immunity, inflammation, tissue connectivity, cellular movement, immune cell trafficking, cell death and survival, and cell-to-cell signaling and interaction.

\section{The candidate patients' severity-relevant features}

Unsupervised clustering with the 104 survival-related genes in all glioma patients (GBM and LGG) revealed that the expression levels of these genes would be higher in most of GBM cases and lower in LGG cases. This property could be applied as an indicator to distinguish patients' risk (Fig. 4). Expression level analysis of the 104 shared genes relative to the expression of the 5 control genes were conducted among all patients with LGG $(n=516)$ and GBM $(n=$ 154) from TCGA. Eighty-six of these genes, however, were screened between the different study cohorts for their signatures; subsequently, the other genes would be skipped here because they could not be validated with different datasets from GEO. For each feature, the selection criteria applicable state that more than $50 \%$ of patients with GBM and LGG must have a different expression tendency relative to that of the control genes. Consequently, 19 features (with 16 genes involved) that met these criteria were filtered and then validated using various microarray datasets (Table 6). Obviously, two control genes, GAPDH and $R P L 13 A$, were filtered out in this study, because the expression levels of survival-related genes relative to

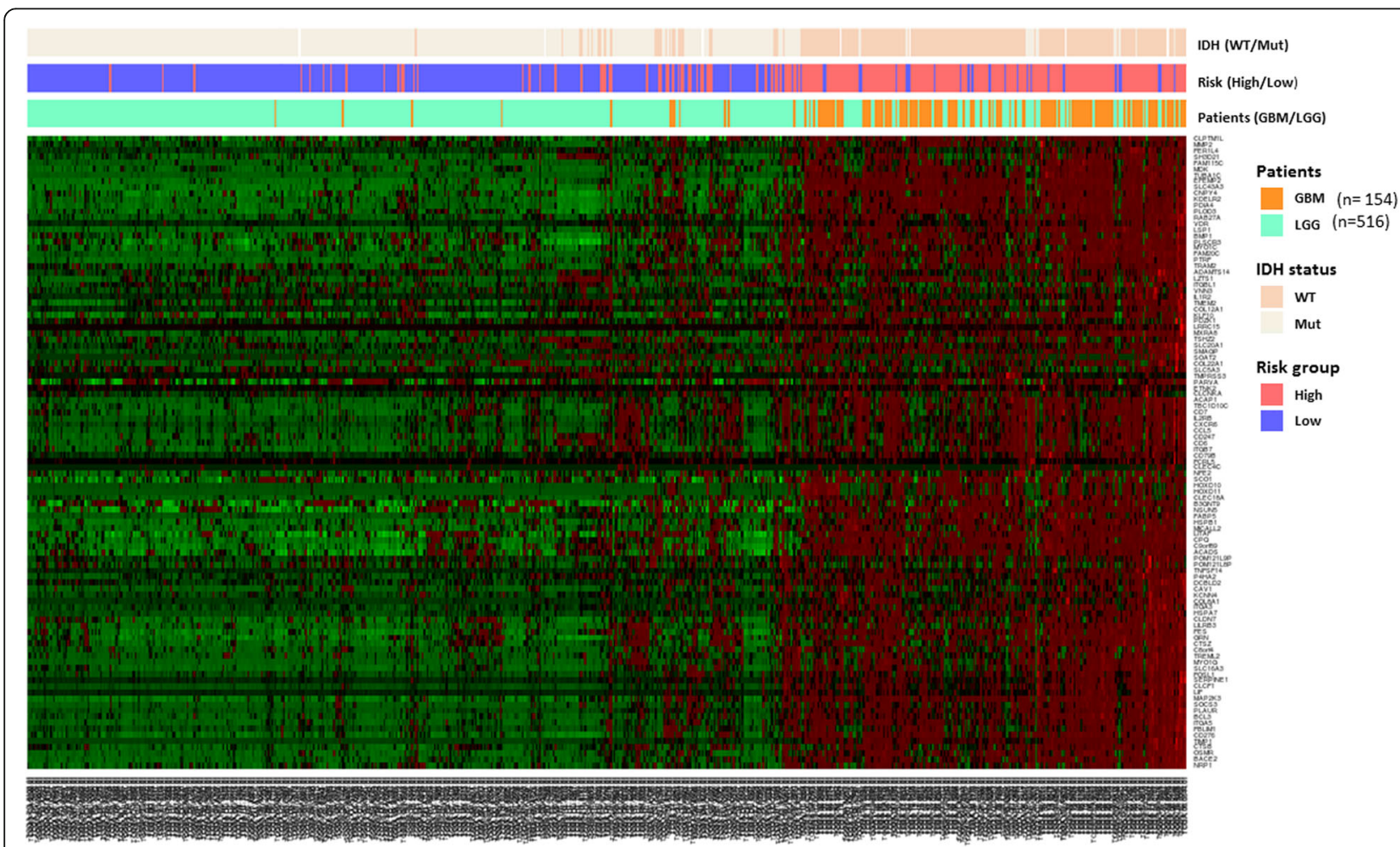

Fig. 4 Heatmap view of the unsupervised clustering of 670 patients with glioma with expression profiles of the 104-gene group (TCGA samples). In the heatmap, the Y-axis represents the 104 genes and the X-axis represents patients with glioma. The expression levels from low to high are represented as a color gradient from green to red, respectively. There are three color bars of the heatmap utilizes different colors to represent IDH status (wild type and mutation), risk group (high/low), and patients with LGG and GBM 
Table 6 Candidate features have different expression level between GBM and LGG

\begin{tabular}{|c|c|c|c|c|c|c|c|c|}
\hline & TCGA & & GSE16011 & & GSE4271 & & GSE4412 & \\
\hline & GBM & LGG & GBM & LGG & GBM & LGG & GBM & LGG \\
\hline CTSZ/IPO8 & $+(79.22 \%)$ & - (65.12\%) & & & & & $+(62.71 \%)$ & - (80.77\%) \\
\hline EFEMP2/IPO8 & $+(78.57 \%)$ & - (89.15\%) & $+(83.02 \%)$ & - (64.22\%) & & & & \\
\hline EFEMP2/SDHA & $+(58.44 \%)$ & - (96.12\%) & $+(52.83 \%)$ & - (85.32\%) & $+(61.84 \%)$ & - (83.33\%) & & \\
\hline EFEMP2/TBP & $+(94.16 \%)$ & - (50.39\%) & $+(81.76 \%)$ & - (64.22\%) & & & $+(79.66 \%)$ & - (65.38\%) \\
\hline ITGA3/IPO8 & $+(52.60 \%)$ & - (88.37\%) & & & & & $+(62.71 \%)$ & - (92.31\%) \\
\hline ITGA5/IPO8 & $+(56.49 \%)$ & - (95.54\%) & $+(60.38 \%)$ & - (79.82\%) & & & & \\
\hline KDELR2/SDHA & + (98.70\%) & - (70.74\%) & $+(83.02 \%)$ & - (64.22\%) & & & & \\
\hline LITAF/SDHA & $+(80.52 \%)$ & - (79.46\%) & $+(88.68 \%)$ & - (54.13\%) & & & & \\
\hline MAP 2 K3/TBP & $+(90.26 \%)$ & - (63.37\%) & & & & & $+(69.49 \%)$ & - (61.54\%) \\
\hline MDK/PO8 & $+(85.06 \%)$ & - (87.02\%) & $+(76.73 \%)$ & - (74.31\%) & & & $+(79.66 \%)$ & - (73.08\%) \\
\hline MICALL2/TBP & $+(83.77 \%)$ & - (53.10\%) & $+(81.76 \%)$ & - (55.96\%) & & & & \\
\hline NRP1/IPO8 & $+(57.79 \%)$ & - (92.83\%) & $+(57.86 \%)$ & - (73.39\%) & $+(86.84 \%)$ & - (70.83\%) & & \\
\hline P4HA2/TBP & $+(57.79 \%)$ & - (85.27\%) & $+(62.89 \%)$ & - (86.24\%) & & & & \\
\hline PDIA4/SDHA & $+(94.81 \%)$ & - (75.78\%) & & & $+(78.95 \%)$ & - (70.83\%) & & \\
\hline PLAUR/TBP & $+(71.43 \%)$ & - (89.73\%) & & & & & $+(67.80 \%)$ & - (92.31\%) \\
\hline PLOD3/SDHA & $+(50.09 \%)$ & - (92.25\%) & $+(84.91 \%)$ & - (55.96\%) & & & & \\
\hline SERPINE1/IPO8 & $+(68.18 \%)$ & - (88.76\%) & $+(67.30 \%)$ & - (77.98\%) & $+(76.32 \%)$ & - (70.83\%) & $+(84.75 \%)$ & - (65.38\%) \\
\hline SERPINE1/TBP & $+(96.10 \%)$ & - (60.08\%) & $+(69.18 \%)$ & - (79.82\%) & & & & \\
\hline SOCS3/IPO8 & $+(50.65 \%)$ & - (92.64\%) & & & & & $+(74.58 \%)$ & - (69.23\%) \\
\hline
\end{tabular}

The positive sign " + " means the expression level of survival-related gene comparing to the control gene (log2 ratio) was higher. The negative sign "-" means the expression level of survival-related gene comparing to the control gene (log2 ratio) was lower. The percentage represents how many patients in GBM or LGG are expressed higher/lower than the control genes

both these control genes did not have clear differences in case of GBM and LGG. Additionally, 16 genes involved in these features had a higher expression in GBM than in LGG.

\section{Effectiveness features for evaluating risks of patients with glioma}

Based on the assumption that patients with GBM $(n=154)$ have a higher risk (short median OS) than those with LGG $(n=516)$ (longer median OS), the construction of a logistic regression model with various combinations of features was repeated. The ten smallest features, namely, CTSZ/IPO8, EFEMP2/IPO8, ITGA5/IPO8, KDELR2/SDHA, MDK/IPO8, MICALL2/TBP, MAP 2 K3/TBP, PLAUR/TBP, SERPINE1/ $T B P$, and SOCS3/IPO8 were utilized to construct the risk model with the lowest AIC value which was 239.51. Therefore, utilizing the signatures of ten genes relative to the three control genes would have the capability to evaluate patient risks.

\section{Patients' risk distinguishable with ten gene signatures}

After screening the importance of features with the logistic regression model, ten of these features would be used to construct the risk models for GBM and LGG. In the GBM study cohort, when the probability that patients belong to the high-risk group was less than 0.35 , they would be clustered into the relatively low-risk group, whereas the LGG risk model attempted to identify relatively high-risk patients when this probability was larger than 0.9. Therefore, GBM patients $(n=154)$ could be divided into the high-risk group $(n=135)$ and low-risk group $(n=19)$; LGG patients $(n=516)$ could also be divided into the low-risk group $(n=364)$ and high-risk group $(n=$ 152). The risk groups shown in the Kaplan-Meier curve (Fig. 5 and Fig. 6) were significantly different (Log rank test, $p<0.01$ ). Moreover, the models were evaluated by repeating the 5 -fold cross-validation 1000 times; the average AUC value of ROC in GBM was 0.986 , and that in LGG was 0.982 . In addition to testing effectiveness of candidate genes which were used to construct risk models against TCGA datasets (RNA-Seq), microarray dataset GSE16011 which include large cases (GBM, $n=159$; LGG, $n=109$ ) and with various grades (G2, G3, and G4) was used to validate it. However, datasets from different platforms, the distribution of overall gene expression level would be varies. Thus, building different risk models for GBM and LGG for various platforms is required. Consequently, the Kaplan-Meier curve showed that GBM 


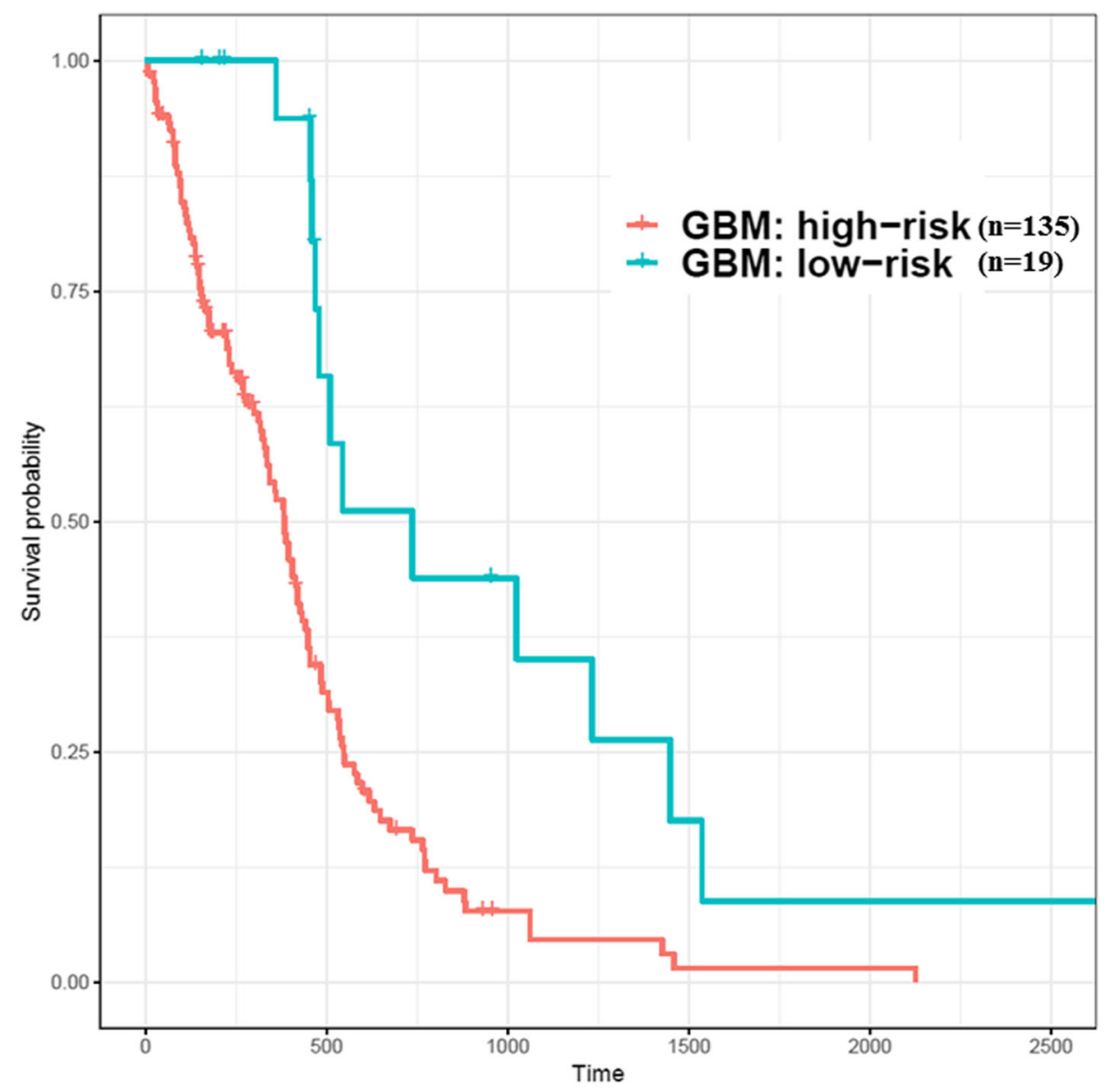

Fig. 5 Patients with GBM were divided into high- and low-risk groups identified based on ten genes (TCGA samples). X-axis: patients' OS duration (days); Y-axis: patients' survival rate. Log rank test between high-risk $(n=135)$ and low-risk $(n=19)$ groups was significant difference $(p<0.01)$

and LGG from GSE16011 can be well distinguished into different risk groups (log rank test, $p<0.01)$ using the candidate features (Fig. 7).

\section{Discussion}

In this study, we identified 104 common survivalrelated genes from patients with gliomas. The effectiveness of these genes was evaluated by constructing prediction models, and the AUC values were estimated to be approximately 0.7 and 0.8 for the GBM and LGG models, respectively, after 1000 iterations of 5 -fold cross-validation. The heatmap (Fig. 4) has shown that expression profiles of these genes are associated with the IDH1 and risk status among patients with gliomas; most of patients with GBM are wild-type IDH1 and have short survival time (high risk), but patients with LGG are mutant-type IDH1 and survive long (low risk). Most of these genes were involved in cell-related signaling pathways that affect cellular proliferation, apoptosis, and angiogenesis. Moreover, of the 104 survival-related genes, 10 could potentially distinguish patients with GBM or LGG into high- and low-risk groups. The expression levels of these ten genes were higher and the survival duration was shorter in patients with high-grade glioma than in those with lower grade glioma.

Identification of survival-related genes in gliomas has been ongoing over the past decade. However, the gene lists identified by our study and the other various research groups [14-29] differ considerably; only 13 common genes (BMP2, CLIC1, EST, IGFBP2, LDHA, LGALS1, MET, MSN, TGALN2, TIMP1, TNC, UPP1, $Z Y X)$ could be identified in at least three studies. These differences may be attributed to two major factors. First, researchers have analyzed glioma datasets from various perspectives; for instance, some studies have discussed some aspects only in patients with high-grade gliomas [14, 20, 23-27, 29], or LGG [21, 28], or at specific checkpoints such as the mitotic spindle checkpoint [19] or ion channel [27]. Second, studies have analyzed different types of datasets obtained from various high-throughput platforms such as microarray or 


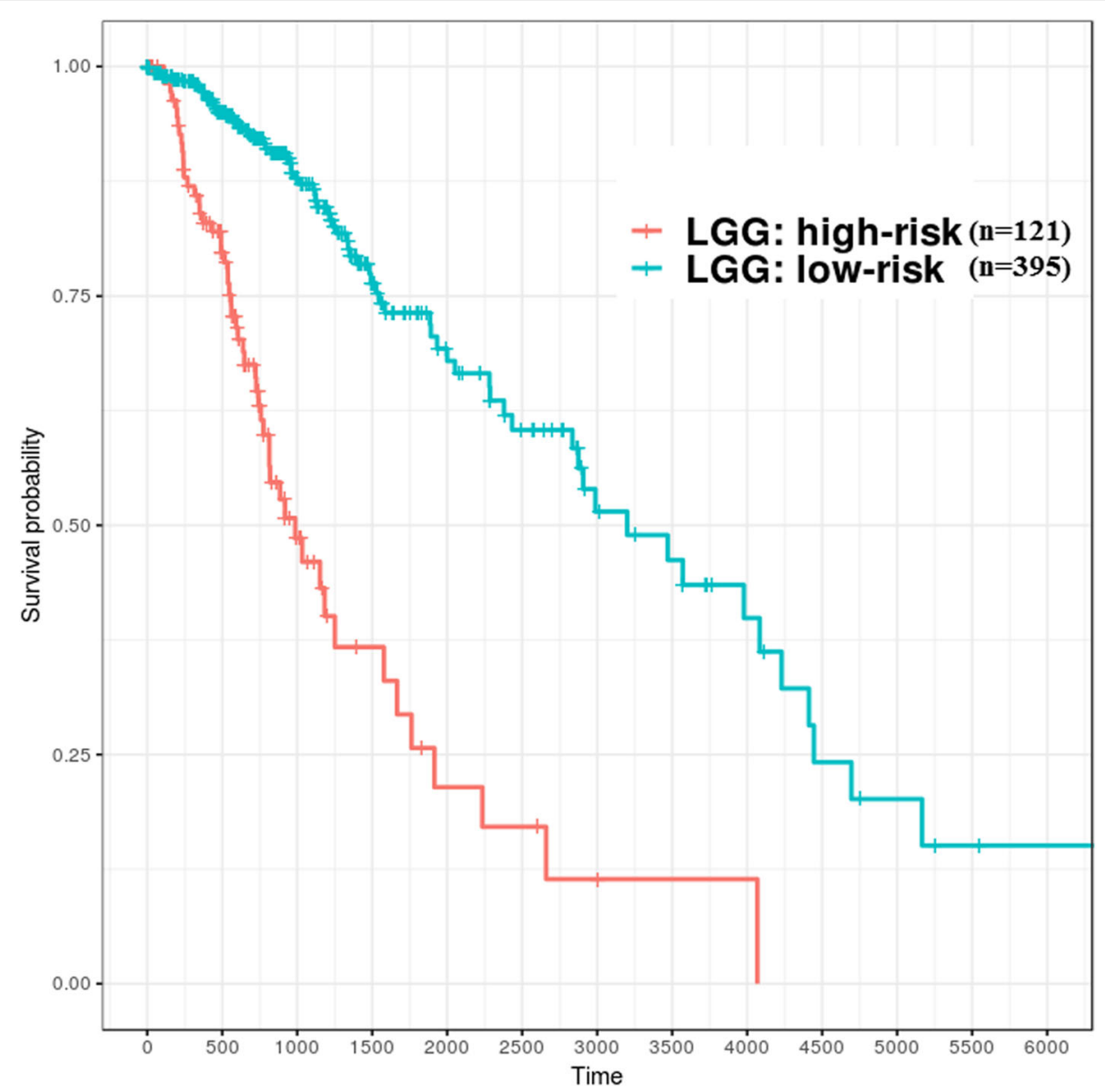

Fig. 6 Patients with LGG were divided into high- and low-risk groups identified based on ten genes (TCGA samples). X-axis: patients' OS duration (days); Y-axis: patients' survival rate. Log rank test between high-risk $(n=121)$ and low-risk $(n=395)$ groups was significant difference $(p<0.01)$

next-generation data. Because of technical limitations, the expression profiles of the same genes detected from different datasets may be inconsistent. For instance, the sequencing data have higher stochastic variability than array data, which would result in a lack of reads in short or low abundance genes [40]. On the other hand, microarray data of gene expression can be affected by probes' cross-hybridization, nonspecific hybridization, redundancy, and annotation [41]. Rather than NGS, microarray analysis has been selected as the initial screening method in most relevant studies. Recently, various research groups have started using NGS data (e.g., RNA-Seq) as the main analysis platform and microarray data as an adjuvant platform to verify results.

Accurate survival prediction through comprehensive indicators is vital for patients with glioma. However, the 104-gene group identified in this study would include parts of those indicators and was also crucial for survival prediction in both types of gliomas; its effectiveness in analyzing the GBM and LGG cohorts demonstrated that there other specific survival-related genes might exist. However, these 104 genes were the basic factors for patients' survival in case of GBM and LGG, because the average AUC value under multiple times of simulation could reach $0.7-0.8$. These genes could be used together with self-specific genes of each type of glioma, to elaborate the regulation networks in various mechanisms. In addition, recent studies have identified crucial glioma imaging features from magnetic resonance imaging (MRI) and have correlated them with patient survival $[42,43]$. The association of imaging and genomic features could be realized and applied in the field of radiogenomics.

The expression level analysis of survival-related genes could have implications; high signatures of genes in patients would be indicative of shorter survival durations in contrast to low signatures of genes, where patients have a longer survival time. Moreover, most of these genes were highly expressed in GBM and the converse is true in case of LGG. However, it is difficult to set the cutoff values to indicate whether gene expression was 

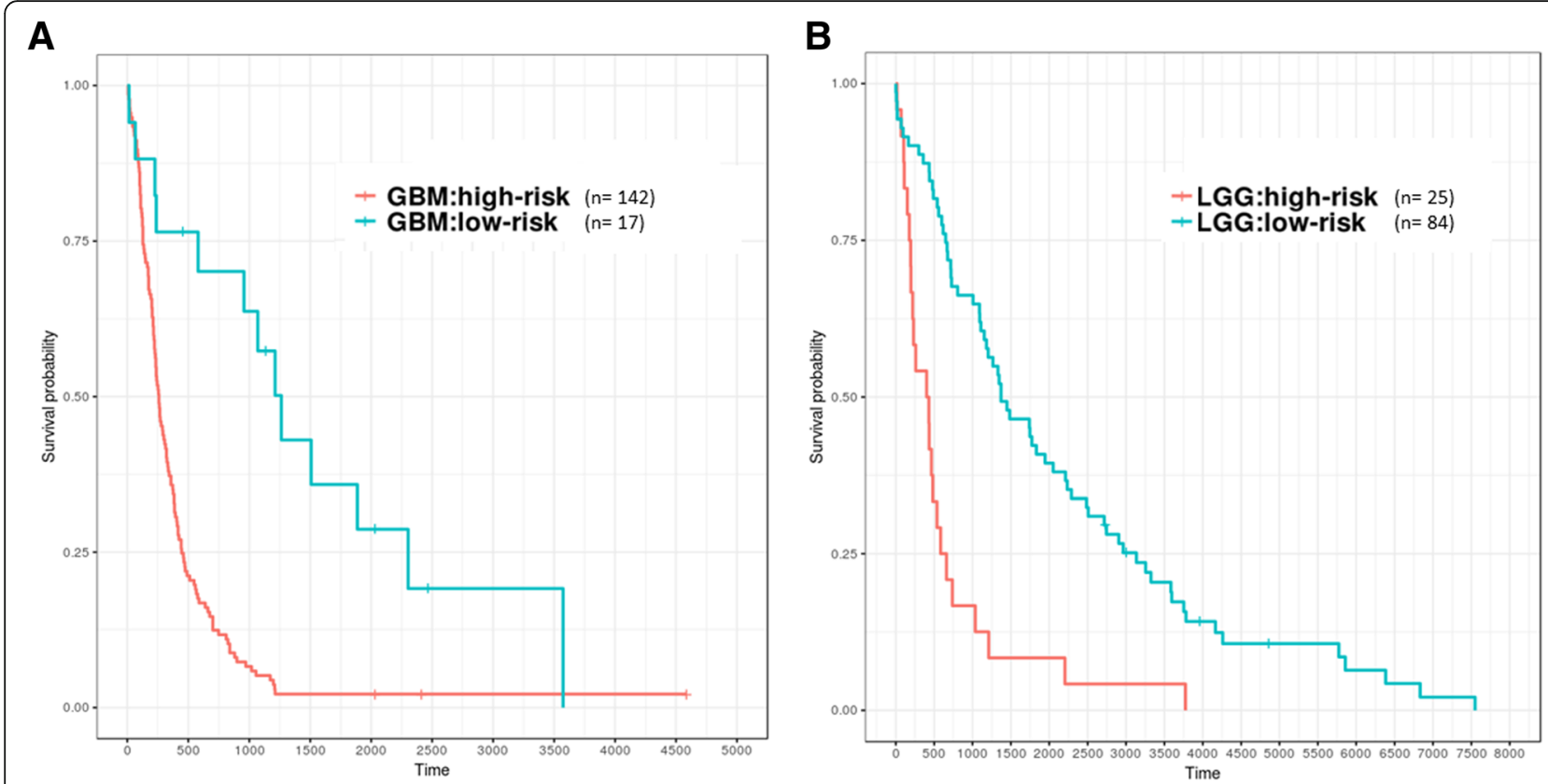

Fig. 7 Patients with GBM and LGG were divided into high- and low-risk groups identified based on ten genes (GEO samples). X-axis: patients' OS duration (days); Y-axis: patients' survival rate. a GBM, log rank test between high-risk $(n=142)$ and low-risk $(n=17)$ groups was significant difference $(p<0.01)$. b LGG, log rank test between high-risk $(n=25)$ and low-risk $(n=84)$ groups was significant difference $(p<0.01)$

high or low, because of individual differences. Therefore, the reference genes (called control genes in this study) would be the target of comparison for survival-relevant genes. Furthermore, in order to have objective indicators consequently, different datasets were used to validate the results from NGS and the minor effectiveness of genes, which was decided by the logistic regression model, was removed.

Survival-relevant risk models were constructed for GBM and LGG; the evaluation related to model performance was larger than 0.95 (average AUC value), which means it could successfully classify patients into

Table $7 \mathrm{IDH} 1$ and $1 \mathrm{p} / 19 \mathrm{q}$ status of high- and low-risk groups of patients with LGG and those with GBM

\begin{tabular}{|c|c|c|c|c|}
\hline & \multicolumn{2}{|l|}{ LGG } & \multicolumn{2}{|l|}{ GBM } \\
\hline & High risk & Low risk & High risk & Low risk \\
\hline$n$ & 121 & 395 & 135 & 19 \\
\hline \multicolumn{5}{|l|}{ IDH1 status } \\
\hline Wild type & $73(60.3 \%)$ & $21(5.3 \%)$ & $130(96.3 \%)$ & $10(52.6 \%)$ \\
\hline Mutation & 47 (38.8\%) & $372(94.2 \%)$ & $2(1.5 \%)$ & $8(42.1 \%)$ \\
\hline Unknown & $1(0.8 \%)$ & $2(0.5 \%)$ & $3(2.2 \%)$ & $1(5.3 \%)$ \\
\hline \multicolumn{5}{|l|}{$1 p / 19 q$ status } \\
\hline Codel & $13(10.7 \%)$ & $156(39.5 \%)$ & & \\
\hline Noncodel & $108(89.3 \%)$ & $239(60.5 \%)$ & $130(96.3 \%)$ & $18(94.7 \%)$ \\
\hline Unknown & & & $5(3.7 \%)$ & $1(5.3 \%)$ \\
\hline \multicolumn{5}{|l|}{ IDH1 and $1 p / 19 q$ status } \\
\hline Wild type and noncodel & $73(60.3 \%)$ & $21(5.3 \%)$ & $126(93.3 \%)$ & $10(52.6 \%)$ \\
\hline Mutation and noncodel & $34(28.1 \%)$ & $216(54.7 \%)$ & $1(0.7 \%)$ & $7(36.8 \%)$ \\
\hline Mutation and codel & $13(10.7 \%)$ & $156(39.5 \%)$ & & \\
\hline Wild type & & & $4(3.0 \%)$ & \\
\hline Mutation & & & $1(0.7 \%)$ & $1(5.3 \%)$ \\
\hline \multicolumn{5}{|l|}{ Codel } \\
\hline Noncodel & $1(0.8 \%)$ & $2(0.5 \%)$ & $3(2.2 \%)$ & $1(5.3 \%)$ \\
\hline
\end{tabular}


different risk groups. In GBM, the survival durations of the low-risk group were better than the high-risk group, and its median OS was larger than 450 days (1.2 years). On the other hand, in LGG, the survival durations of the high-risk group were worse than that in the low-risk group and the median OS time was shorter than 2700 days (7.4 years). Recent studies [44-47] have demonstrated that gliomas could be divided into multiple subtypes based on various molecular features such as $I D H 1$ mutation/wild type and chromosome $1 \mathrm{p} / 19 \mathrm{q}$ noncodeletion/codeletion. Generally, IDH1 mutation and 1p/19q codeletion are favorable prognostic factors for patients with gliomas. Patients with GBM $(n=154)$ from TCGA, in addition to the following status: chromosome $1 \mathrm{p} / 19 \mathrm{q}$ was not available (NA), all showed noncodeletion; only 10 patients showed IDH1 mutation. In the low-risk group $(n=19)$ of GBM, as identified using the logistic regression model, 8 patients had the $I D H 1$ mutant. This result indicated that $80 \%$ of patients with $I D H 1$ mutation would be clustered into the relative low-risk group of GBM against the risk prediction model. Unlike GBM,
IDH1 was mutated in most patients $(n=419)$ and fewer patients $(n=94)$ had the wild-type IDH1 in the LGG $(n=516)$ datasets from TCGA. In addition, with regards to the status observation of chromosome $1 \mathrm{p} / 19 \mathrm{q}$ for patients with LGG, parts $(n=347)$ of them were noncodeletion and the others $(n=169)$ were codeletion. According to the relative high-risk group $(n=121)$ of LGG clustered by our constructed model, most of patients had wild-type IDH1 $(n=73)$ and $1 \mathrm{p} / 19 \mathrm{q}-$ noncodeletion $(n=108)$, accounting for 60.3 and $89.3 \%$ of the cases, respectively (Table 7). Therefore, the molecular features of the high- and low-risk groups identified using the signatures of these ten genes were in accordance with the results of previous studies. However, the risk model could not directly classify patients with wild-type IDH1 into different risk groups well. For instance, $22.3 \%(n=21)$ and $77.7 \%(n=73)$ of patients with wild-type IDH1 in the LGG cohort $(n=94)$ were identified as low and high risk, respectively (Table 7); the survival curves of both risk groups could not be separated significantly, especially those representing

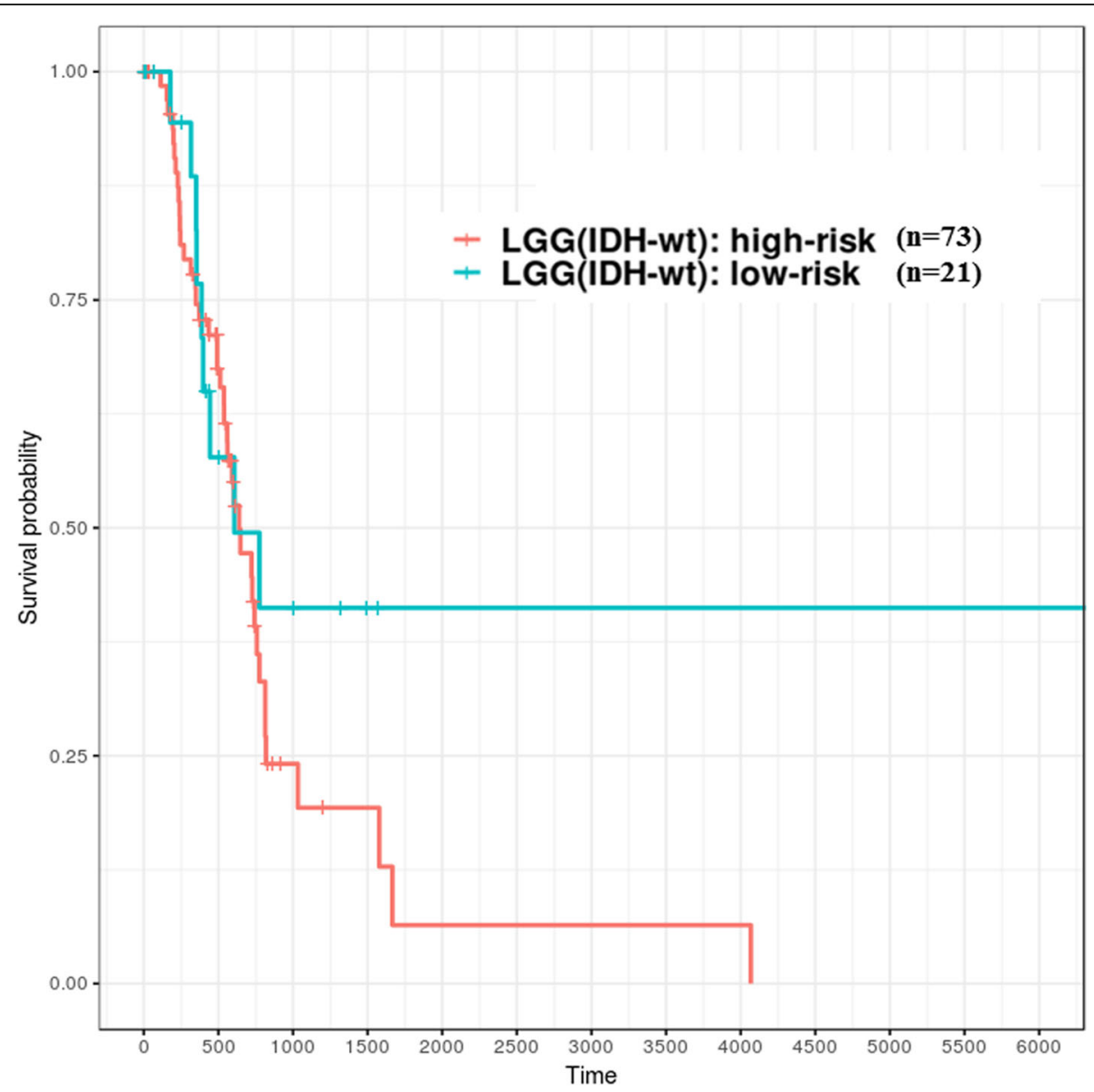

Fig. 8 High- and low-risk groups of patients with LGG having wild-type IDH1 identified based on ten genes (TCGA samples). X-axis: patients' OS duration (days); Y-axis: patients' survival rate. Both risk groups could not be separated well; log rank test, $p=0.248$ was not statistically significant 
less than 750 days of survival durations (Fig. 8). Therefore, further identification of other effective predictors is required to evaluate how patients with better survival can be efficiently distinguished from patients with glioma having wild-type IDH1. However, the risk model could classify patients with mutant-type IDH1 into different risk groups well in LGG cohort $(n=419)$. There are $47(11.2 \%)$ and 372 $(88.8 \%)$ of patients belong to high- and low-risk groups, respectively (Fig. 9). The high-risk group of patients with $I D H 1$ mutation might be associated with DNA methylation, which has indicated in the study based on the molecular profiling analysis [48].

The expression level of the ten aforementioned genes tended to gradually decrease from GBM to LGGs (Fig. 10). The OS duration of patients decreased upon high gene expression but increased upon low gene expression. Several of these genes have been reported in previous studies; for instance, EFEMP2 was indicated as a potent oncogene in glioma and a target for glioma treatment [49], the overexpression of SERPINE1 (PAI-1) was significantly correlated with shorter survival durations in patients with GBM [50], the expression of ITGA5 might be correlated to the regulation of cell proliferation and invasiveness in GBM, because targeting ITGA5 using miR-330-5p could affect these cell events [51], and the biological function of PLAUR could be related to glioma cell invasion and angiogenesis [52]. In addition, the ten genes could be mapped to the various hallmarks of cancer with literature survey (Table 8). Therefore, this 10-gene group might have potential prognostic value for patients with glioma.

\section{Conclusions}

In summary, the 104 genes identified, which are common between patients with GBM and those with LGG, can be used as core genes related to patient survival. Of these, 10 genes (CTSZ, EFEMP2, ITGA5, KDELR2, MDK, MICALL2, MAP 2 K3, PLAUR, SERPINE1, and $S O C S 3)$ can potentially serve as indicators to classify

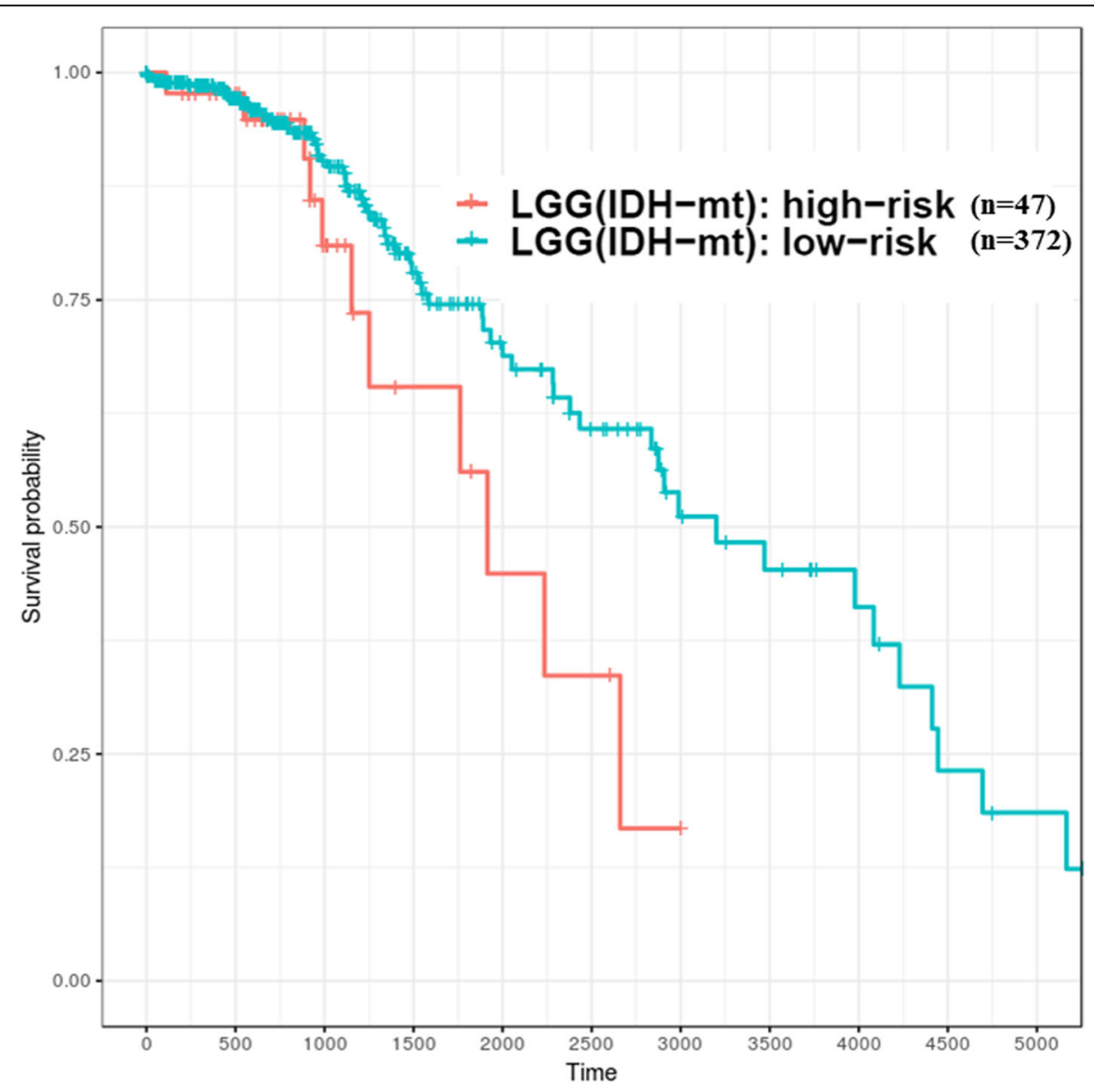

Fig. 9 High- and low-risk groups of patients with LGG having mutant-type IDH1 identified based on ten genes (TCGA samples). X-axis: patients' OS duration (days); Y-axis: patients' survival rate. Log rank test between high-risk $(n=47)$ and low-risk $(n=372)$ groups was significant difference $(p<0.05)$ 


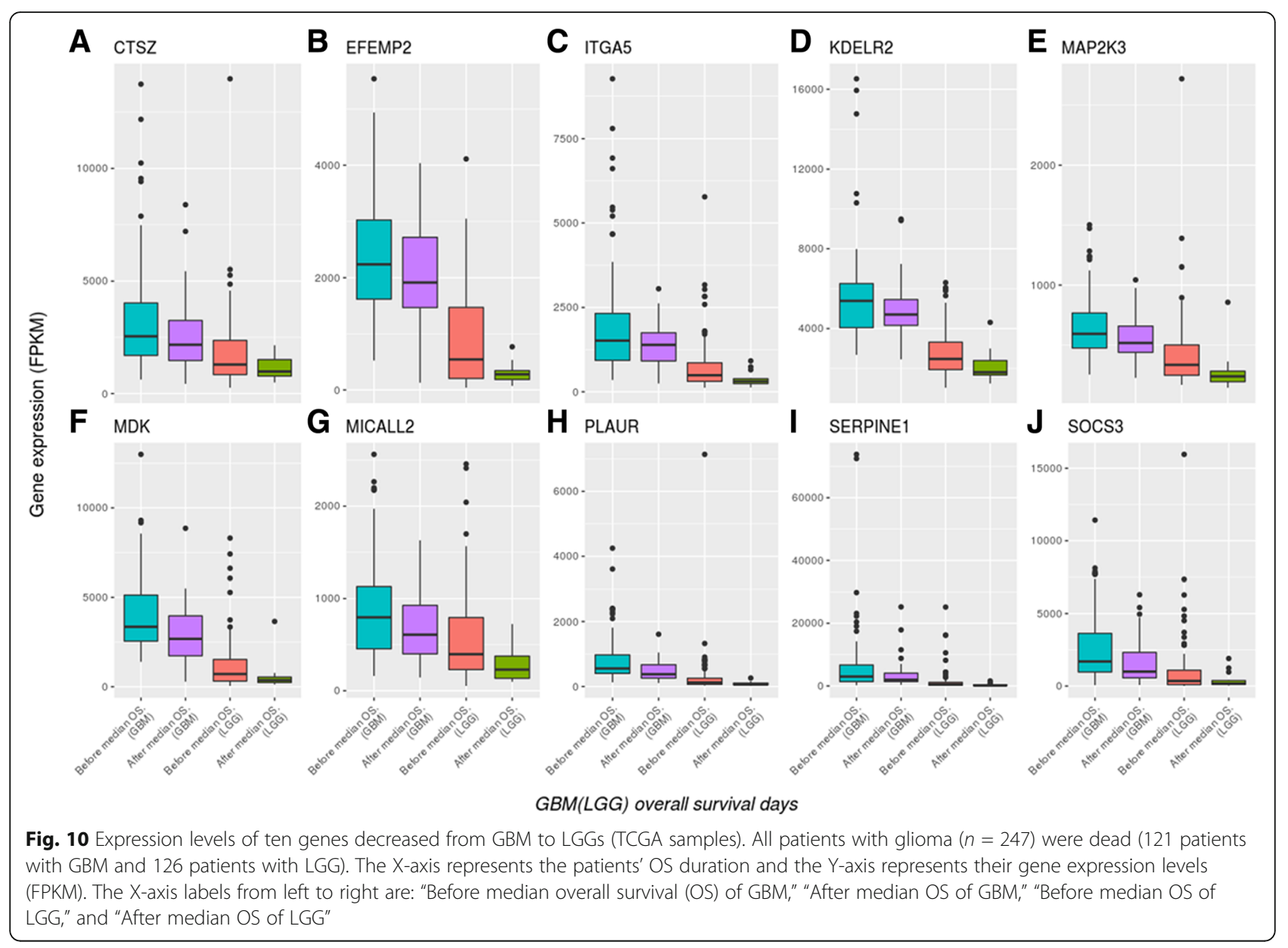

Table 8 The cancer hallmarks mapping of the ten genes

\begin{tabular}{|c|c|c|c|}
\hline Gene symbol & MSigDB (Hallmark) [53] & Hallmarks of cancer & Ref. \\
\hline CTSZ & IL2/JAK/STAT5 signaling & $\begin{array}{l}\text { sustaining proliferative signaling, } \\
\text { activating invasion and metastasis }\end{array}$ & [54] \\
\hline EFEMP2 & Epithelial mesenchymal transition & $\begin{array}{l}\text { sustaining proliferative signaling, } \\
\text { activating invasion and metastasis }\end{array}$ & [49] \\
\hline ITGA5 & Epithelial mesenchymal transition, Inflammatory response & All & [55] \\
\hline KDELR2 & & activating invasion and metastasis & [56] \\
\hline MDK & Estrogen response late, Apical junction & $\begin{array}{l}\text { sustaining proliferative signaling, } \\
\text { activating invasion and metastasis }\end{array}$ & [57] \\
\hline MICALL2 & & sustaining proliferative signaling & [58] \\
\hline MAP 2 K3 & $\begin{array}{l}\text { TNF-a signaling via NF-kB, PI3K/AKT/mTOR signaling, mTORC1 signaling, } \\
\text { Heme metabolism }\end{array}$ & sustaining proliferative signaling & [59] \\
\hline PLAUR & TNF-alpha signaling via NF-kB, Cholesterol homeostasis & $\begin{array}{l}\text { activating invasion and metastasis, } \\
\text { inducing angiogenesis }\end{array}$ & {$[52,60-62]$} \\
\hline SERPINE1 & $\begin{array}{l}\text { TNF- alpha signaling via NF-kB, Hypoxia, TGF-beta signaling, } \\
\text { Complement, Epithelial mesenchymal transition, Inflammatory response, } \\
\text { Xenobiotic metabolism, UV response down, Coagulation }\end{array}$ & inducing angiogenesis & [63] \\
\hline SOCS3 & $\begin{array}{l}\text { TNF- alpha signaling via NF-kB, IL6/JAK/STAT3 signaling, } \\
\text { Interferon gamma response }\end{array}$ & $\begin{array}{l}\text { sustaining proliferative signaling, } \\
\text { tumor-promoting inflammation }\end{array}$ & [64] \\
\hline
\end{tabular}


patients with gliomas into different risk groups and could be used to estimate the prognosis of patients with gliomas. Moreover, the expression profiles of these potential biomarkers could be correlated to the molecular subtypes of patients, such as IDH1/2 mutation/wild type and chromosome $1 \mathrm{p} / 19 \mathrm{q}$ codeletion/noncodeletion.

\section{Additional file}

Additional file 1: Table S1. Title: 104 common survival-related genes were identified from patients with GBM and those with LGG. Description: Summarization of Cox model results for 104 survival-relevant common genes between LGG and GBM with table. (PDF $38 \mathrm{~kb}$ )

\section{Acknowledgements}

We thank Dr. Shiu-Wen Huang for mapping the potential biomarkers to the hallmarks of cancer.

\section{Funding}

Publication of this article was funded by a grant from Taipei Medical University Hospital (106TMUH-SP-02).

\section{Availability of data and materials}

The datasets used and analyzed during the current study available from published databases, such as TCGA projects (TCGA-LGG and TCGA-GBM) https://cancergenome.nih.gov/, level 3 RNA-Seq datasets and their clinical information and GEO microarray datasets (GSE16011, GSE4412, and GSE4271) https://www.ncbi.nlm.nih.gov/geo/.

\section{About this supplement}

This article has been published as part of BMC Medical Genomics Volume 11 Supplement 7, 2018: Selected articles from the 17th International Conference on Bioinformatics (InCoB 2018): medical genomics. The full contents of the supplement are available online at https://bmcmedgenomics.biomedcentral.com/ articles/supplements/volume-11-supplement-7.

\section{Authors' contributions}

JBKH conceived and designed the experiments. JBKH performed the experiments. JBKH and GAL analyzed the data. JBKH wrote the manuscript with revision by TYL and THC. Data and results were interpreted by JBKH, and CYC. The study was supervised by CYC. All authors read and approved the final manuscript.

\section{Ethics approval and consent to participate}

Not applicable.

\section{Consent for publication}

Not applicable.

\section{Competing interests}

The authors declare that they have no competing interests.

\section{Publisher's Note}

Springer Nature remains neutral with regard to jurisdictional claims in published maps and institutional affiliations.

\footnotetext{
Author details

'Department of Medical Research, Taipei Medical University Hospital, Taipei 110, Taiwan. ${ }^{2}$ Graduate Institute of Biomedical Informatics, Taipei Medical University, Taipei 110, Taiwan. ${ }^{3}$ Warshel Institute for Computational Biology, The Chinese University of Hong Kong, Shenzhen 518172, China. ${ }^{4}$ School of Science and Engineering, The Chinese University of Hong Kong, Shenzhen 518172, China. ${ }^{5}$ School of Life and Health Science, The Chinese University of Hong Kong, Shenzhen 518172, China. ${ }^{6}$ Research Center of Translational Imaging, College of Medicine, Taipei Medical University, Taipei 110, Taiwan. ${ }^{7}$ Department of Radiology, School of Medicine, College of Medicine, Taipei Medical University, Taipei 110 , Taiwan. ${ }^{8}$ Department of Medical Imaging and
}

Imaging Research Center, Taipei Medical University Hospital, Taipei Medical University, Taipei 110, Taiwan. ${ }^{9}$ Department of Radiology, Tri-Service General Hospital, Taipei 114, Taiwan. ${ }^{10}$ Department of Radiology, National Defense Medical Center, Taipei 114, Taiwan.

Received: 26 May 2018 Accepted: 6 February 2019

Published: 20 March 2019

\section{References}

1. Deorah S, Lynch CF, Sibenaller ZA, Ryken TC. Trends in brain cancer incidence and survival in the United States: surveillance, epidemiology, and end results program, 1973 to 2001. Neurosurg Focus. 2006;20(4):E1.

2. Louis DN, Ohgaki H, Wiestler OD, Cavenee WK, Burger PC, Jouvet A, Scheithauer BW, Kleihues P. The 2007 WHO classification of tumours of the central nervous system. Acta Neuropathol. 2007;114(2):97-109.

3. Ohgaki H, Dessen P, Jourde B, Horstmann S, Nishikawa T, Di Patre PL, Burkhard C, Schuler D, Probst-Hensch NM, Maiorka PC, et al. Genetic pathways to glioblastoma: a population-based study. Cancer Res. 2004;64(19):6892-9.

4. Ohgaki H, Kleihues P. Epidemiology and etiology of gliomas. Acta Neuropathol. 2005;109(1):93-108.

5. Stewart LA. Chemotherapy in adult high-grade glioma: a systematic review and meta-analysis of individual patient data from 12 randomised trials. Lancet. 2002;359(9311):1011-8.

6. Stupp R, Hegi ME, Mason WP, van den Bent MJ, Taphoorn MJ, Janzer RC, Ludwin SK, Allgeier A, Fisher B, Belanger K, et al. Effects of radiotherapy with concomitant and adjuvant temozolomide versus radiotherapy alone on survival in glioblastoma in a randomised phase III study: 5-year analysis of the EORTC-NCIC trial. Lancet Oncol. 2009;10(5):459-66.

7. Bauman GLK, Larson D, Stalpers L, Leighton C, Fisher B, Wara W, MacDonald D, Stitt L, Cairncross JG. Pretreatment factors predict overall survival for patients with low-grade glioma: a recursive partitioning analysis. Int J Radiat Oncol Biol Phys. 1999;45(4):923-9.

8. Johannesen TB, Langmark F, Lote K. Progress in long-term survival in adult patients with supratentorial low-grade gliomas: a population-based study of 993 patients in whom tumors were diagnosed between 1970 and 1993. J Neurosurg. 2003;99(5):854-62.

9. Jiang T, Mao Y, Ma W, Mao Q, You Y, Yang X, Jiang C, Kang C, Li X, Chen L, et al. CGCG clinical practice guidelines for the management of adult diffuse gliomas. Cancer Lett. 2016;375(2):263-73.

10. Kros JM, Gorlia T, Kouwenhoven MC, Zheng PP, Collins VP, Figarella-Branger D, Giangaspero F, Giannini C, Mokhtari K, Mork SJ, et al. Panel review of anaplastic oligodendroglioma from European Organization For Research and Treatment of Cancer Trial 26951: assessment of consensus in diagnosis, influence of 1p/19q loss, and correlations with outcome. J Neuropathol Exp Neurol. 2007;66(6):545-51.

11. Sorlie T, Perou CM, Tibshirani R, Aas T, Geisler S, Johnsen H, Hastie T, Eisen $M B$, van de Rijn M, Jeffrey SS, et al. Gene expression patterns of breast carcinomas distinguish tumor subclasses with clinical implications. Proc Natl Acad Sci U S A. 2001;98(19):10869-74.

12. Valk PJ, Verhaak RG, Beijen MA, Erpelinck CA, Barjesteh van Waalwijk van Doorn-Khosrovani S, Boer JM, Beverloo HB, Moorhouse MJ, van der Spek PJ, Lowenberg B, et al. Prognostically useful gene-expression profiles in acute myeloid leukemia. N Engl J Med. 2004;350(16):1617-28.

13. Nutt CL, Mani DR, Betensky RA, Tamayo P, Cairncross JG, Ladd C, Pohl U, Hartmann C, McLaughlin ME, Batchelor TT, et al. Gene expression-based classification of malignant gliomas correlates better with survival than histological classification. Cancer Res. 2003;63(7):1602-7.

14. Freije WA, Castro-Vargas FE, Fang Z, Horvath S, Cloughesy T, Liau LM, Mischel PS, Nelson SF. Gene expression profiling of gliomas strongly predicts survival. Cancer Res. 2004;64(18):6503-10.

15. Petalidis LP, Oulas A, Backlund M, Wayland MT, Liu L, Plant K, Happerfield L, Freeman TC, Poirazi P, Collins VP. Improved grading and survival prediction of human astrocytic brain tumors by artificial neural network analysis of gene expression microarray data. Mol Cancer Ther. 2008;7(5):1013-24.

16. Phillips HS, Kharbanda S, Chen R, Forrest WF, Soriano RH, Wu TD, Misra A, Nigro JM, Colman H, Soroceanu L, et al. Molecular subclasses of high-grade glioma predict prognosis, delineate a pattern of disease progression, and resemble stages in neurogenesis. Cancer Cell. 2006;9(3):157-73.

17. Shirahata M, Iwao-Koizumi K, Saito S, Ueno N, Oda M, Hashimoto N, Takahashi JA, Kato K. Gene expression-based molecular diagnostic system 
for malignant gliomas is superior to histological diagnosis. Clin Cancer Res 2007;13(24):7341-56.

18. Shirahata M, Oba S, Iwao-Koizumi K, Saito S, Ueno N, Oda M, Hashimoto N, Ishii S, Takahashi JA, Kato K. Using gene expression profiling to identify a prognostic molecular spectrum in gliomas. Cancer Sci. 2009;100(1):165-72.

19. Bie L, Zhao G, Cheng P, Rondeau G, Porwollik S, Ju Y, Xia XQ, McClelland M. The accuracy of survival time prediction for patients with glioma is improved by measuring mitotic spindle checkpoint gene expression. PLoS One. 2011;6(10):e25631.

20. Bonato V, Baladandayuthapani V, Broom BM, Sulman EP, Aldape KD, Do KA. Bayesian ensemble methods for survival prediction in gene expression data. Bioinformatics. 2011;27(3):359-67.

21. Chen B, Liang T, Yang P, Wang H, Liu Y, Yang F, You G. Classifying lower grade glioma cases according to whole genome gene expression. Oncotarget. 2016;7(45):74031-42.

22. Kawaguchi A, Yajima N, Komohara Y, Aoki H, Tsuchiya N, Homma J, Sano M, Natsumeda M, Uzuka T, Saitoh A, et al. Identification and validation of a gene expression signature that predicts outcome in malignant glioma patients. Int J Oncol. 2012;40(3):721-30.

23. Kawaguchi A, Yajima N, Tsuchiya N, Homma J, Sano M, Natsumeda M, Takahashi H, Fujii Y, Kakuma T, Yamanaka R. Gene expression signaturebased prognostic risk score in patients with glioblastoma. Cancer Sci. 2013; 104(9):1205-10.

24. Lu J, Cowperthwaite MC, Burnett MG, Shpak M. Molecular predictors of long-term survival in glioblastoma multiforme patients. PLoS One. 2016; 11(4):e0154313.

25. Rich JN, Hans C, Jones B, Iversen ES, McLendon RE, Rasheed BK, Dobra A, Dressman HK, Bigner DD, Nevins JR, et al. Gene expression profiling and genetic markers in glioblastoma survival. Cancer Res. 2005;65(10):4051-8.

26. Ruano Y, Mollejo M, Camacho Fl, Rodriguez de Lope A, Fiano C, Ribalta T, Martinez $\mathrm{P}$, Hernandez-Moneo JL, Melendez B. Identification of survivalrelated genes of the phosphatidylinositol $3^{\prime}$-kinase signaling pathway in glioblastoma multiforme. Cancer. 2008;112(7):1575-84.

27. Wang R, Gurguis Cl, Gu W, Ko EA, Lim I, Bang H, Zhou T, Ko JH. lon channel gene expression predicts survival in glioma patients. Sci Rep. 2015;5:11593.

28. Zhang YA, Zhou Y, Luo X, Song K, Ma X, Sathe A, Girard L, Xiao G, Gazdar AF. SHOX2 is a potent independent biomarker to predict survival of WHO grade II-III diffuse gliomas. EBioMedicine. 2016;13:80-9.

29. Kim H, Bredel M. Predicting survival by cancer pathway gene expressionprofiles in the TCGA. In: Bioinformatics and Biomedicine Workshops (BIBMW), 2012 IEEE International Conference 2012; 2012. p. 872-5.

30. Trapnell C, Williams BA, Pertea G, Mortazavi A, Kwan G, van Baren MJ, Salzberg SL, Wold BJ, Pachter L. Transcript assembly and quantification by RNA-Seq reveals unannotated transcripts and isoform switching during cell differentiation. Nat Biotechnol. 2010;28(5):511-5.

31. Bolstad BM, Irizarry RA, Astrand M, Speed TP. A comparison of normalization methods for high density oligonucleotide array data based on variance and bias. Bioinformatics. 2003;19(2):185-93.

32. Cox DR. Regression models and life-tables. J R Stat Soc. 1972;34(2):187-220.

33. Ishwaran $H$, Kogalur UB, Blackstone EH, Lauer MS. Random survival forests. Ann Appl Statist. 2008:2(3):841-60.

34. U.B. IHaK. Random survival forests for R. R News. 2007;7(2):25-31.

35. U.B. IHaK: Random Forests for Survival, Regression, and Classification (RFSRC), R package version 2.5.0. 2017.

36. Ben-Ari Fuchs S, Lieder I, Stelzer G, Mazor Y, Buzhor E, Kaplan S, Bogoch Y, Plaschkes I, Shitrit A, Rappaport N, et al. GeneAnalytics: an integrative gene set analysis tool for next generation sequencing, RNAseq and microarray data. OMICS. 2016;20(3):139-51

37. Huang DW, Sherman BT, Lempicki RA. Bioinformatics enrichment tools: paths toward the comprehensive functional analysis of large gene lists. Nucleic Acids Res. 2009;37(1):1-13.

38. Huang DW, Sherman BT, Lempicki RA. Systematic and integrative analysis of large gene lists using DAVID bioinformatics resources. Nat Protoc. 2009:4(1):44-57.

39. Kreth S, Heyn J, Grau S, Kretzschmar HA, Egensperger R, Kreth FW. Identification of valid endogenous control genes for determining gene expression in human glioma. Neuro-Oncology. 2010;12(6):570-9.

40. Nazarov PV, Muller A, Kaoma T, Nicot N, Maximo C, Birembaut P, Tran NL, Dittmar G, Vallar L. RNA sequencing and transcriptome arrays analyses show opposing results for alternative splicing in patient derived samples. BMC Genomics. 2017;18(1):443.
41. Zhao S, Fung-Leung WP, Bittner A, Ngo K, Liu X. Comparison of RNA-Seq and microarray in transcriptome profiling of activated T cells. PLoS One. 2014;9(1):e78644.

42. Liu TT, Achrol AS, Mitchell LA, Rodriguez SA, Feroze A, Iv M, Kim C, Chaudhary N, Gevaert O, Stuart JM, et al. Magnetic resonance perfusion image features uncover an angiogenic subgroup of glioblastoma patients with poor survival and better response to antiangiogenic treatment. NeuroOncology. 2017;19(7):997-1007.

43. Itakura H, Achrol AS, Mitchell LA, Loya JJ, Liu T, Westbroek EM, Feroze AH, Rodriguez S, Echegaray S, Azad TD, et al. Magnetic resonance image features identify glioblastoma phenotypic subtypes with distinct molecular pathway activities. Sci Transl Med. 2015;7(303):303ra138.

44. Hu X, Martinez-Ledesma E, Zheng S, Kim H, Barthel F, Jiang T, Hess KR, Verhaak RGW. Multigene signature for predicting prognosis of patients with 1p19q co-deletion diffuse glioma. Neuro-Oncology. 2017;19(6):786-95.

45. Hu N, Richards R, Jensen R. Role of chromosomal 1p/19q co-deletion on the prognosis of oligodendrogliomas: a systematic review and meta-analysis. Interdiscip Neurosurg: Adv Tech Case Manag. 2016;5:58-63.

46. Chen JR, Yao Y, Xu HZ, Qin ZY. Isocitrate dehydrogenase (IDH)1/2 mutations as prognostic markers in patients with glioblastomas. Medicine (Baltimore). 2016;95(9):e2583.

47. Cohen AL, Holmen SL, Colman H. IDH1 and IDH2 mutations in gliomas. Curr Neurol Neurosci Rep. 2013;13(5):345.

48. Ceccarelli M, Barthel FP, Malta TM, Sabedot TS, Salama SR, Murray BA, Morozova O, Newton Y, Radenbaugh A, Pagnotta SM, et al. Molecular profiling reveals biologically discrete subsets and pathways of progression in diffuse glioma. Cell. 2016;164(3):550-63.

49. Wang L, Chen Q, Chen Z, Tian D, Xu H, Cai Q, Liu B, Deng G. EFEMP2 is upregulated in gliomas and promotes glioma cell proliferation and invasion. Int J Clin Exp Pathol. 2015;8(9):10385-93.

50. Colin C, Voutsinos-Porche B, Nanni I, Fina F, Metellus P, Intagliata D, Baeza $\mathrm{N}$, Bouvier C, Delfino C, Loundou A, et al. High expression of cathepsin B and plasminogen activator inhibitor type-1 are strong predictors of survival in glioblastomas. Acta Neuropathol. 2009;1 18(6):745-54.

51. Feng L, Ma J, Ji H, Liu Y, Hu W. miR-330-5p suppresses glioblastoma cell proliferation and invasiveness through targeting ITGA5. Biosci Rep. 2017; 37(3):1-9.

52. Lakka SS, Gondi CS, Yanamandra N, Dinh DH, Olivero WC, Gujrati M, Rao JS. Synergistic down-regulation of urokinase plasminogen activator receptor and matrix metalloproteinase-9 in SNB19 glioblastoma cells efficiently inhibits glioma cell invasion, angiogenesis, and tumor growth. Cancer Res. 2003:63(10):2454-61.

53. Liberzon A, Birger C, Thorvaldsdottir H, Ghandi M, Mesirov JP, Tamayo P. The Molecular Signatures Database (MSigDB) hallmark gene set collection. Cell Syst. 2015;1 (6):417-25.

54. Seton-Rogers S. Microenvironment: source influences function. Nat Rev Cancer. 2014;14(11):704-5.

55. Bianconi D, Unseld M, Prager GW. Integrins in the spotlight of cancer. Int $J$ Mol Sci. 2016;17(12):2037.

56. Ruggiero C, Fragassi G, Grossi M, Picciani B, Di Martino R, Capitani M, Buccione R, Luini A, Sallese M. A Golgi-based KDELR-dependent signalling pathway controls extracellular matrix degradation. Oncotarget. 2015;6(5):3375-93.

57. Muramatsu T. Midkine, a heparin-binding cytokine with multiple roles in development, repair and diseases. Proc Jpn Acad Ser B Phys Biol Sci. 2010; 86(4):410-25.

58. Deng $W$, Wang $Y$, Zhao $S$, Zhang $Y$, Chen $Y$, Zhao $X$, Liu L, Sun $S$, Zhang L, Ye B, et al. MICAL1 facilitates breast cancer cell proliferation via ROS-sensitive ERK/cyclin D pathway. J Cell Mol Med. 2018;22(6): 3108-18.

59. Solomon $\mathrm{H}$, Madar $\mathrm{S}$, Rotter $\mathrm{V}$. Mutant p53 gain of function is interwoven into the hallmarks of cancer. J Pathol. 2011;225(4):475-8.

60. Al-Souhibani N, Al-Ahmadi W, Hesketh JE, Blackshear PJ, Khabar KS. The RNA-binding zinc-finger protein tristetraprolin regulates AU-rich mRNAs involved in breast cancer-related processes. Oncogene. 2010;29(29):4205-15.

61. Khabar KS. Hallmarks of cancer and AU-rich elements. Wiley Interdiscip Rev RNA. 2017;8(1):1368.

62. Montero L, Nagamine Y. Regulation by p38 mitogen-activated protein kinase of adenylate- and uridylate-rich element-mediated urokinase-type plasminogen activator (UPA) messenger RNA stability and UPA-dependent in vitro cell invasion. Cancer Res. 1999;59(20):5286-93. 
63. Mazzoccoli G, Pazienza V, Panza A, Valvano MR, Benegiamo G, Vinciguerra M, Andriulli A, Piepoli A. ARNTL2 and SERPINE1: potential biomarkers for tumor aggressiveness in colorectal cancer. J Cancer Res Clin Oncol. 2012; 138(3):501-11.

64. Rigby RJ, Simmons JG, Greenhalgh CJ, Alexander WS, Lund PK. Suppressor of cytokine signaling 3 (SOCS3) limits damage-induced crypt hyperproliferation and inflammation-associated tumorigenesis in the colon. Oncogene. 2007;26(33):4833-41.

Ready to submit your research? Choose BMC and benefit from:

- fast, convenient online submission

- thorough peer review by experienced researchers in your field

- rapid publication on acceptance

- support for research data, including large and complex data types

- gold Open Access which fosters wider collaboration and increased citations

- maximum visibility for your research: over $100 \mathrm{M}$ website views per year

At $\mathrm{BMC}$, research is always in progress.

Learn more biomedcentral.com/submissions 